\title{
PKM DESA WISATA SEHAT: OUTBOUND DAN EDUKASI KESEHATAN
}

\author{
Sitti Nur Djannah ${ }^{1}$, Surahma Asti Mulasari ${ }^{2}$, Sulistyawati ${ }^{* 3,}$ Tri Wahyuni Sukesi ${ }^{4}$, Fatwa \\ Tentama $^{5}$ \\ 1,2,3,4,5Fakultas Kesehatan Masyarakat, Universitas Ahmad Dahlan \\ Jalan Prof Dr Soepomo, Warungboto, Umbulharjo, Yogyakarta Telp (0274) 563515 \\ *E-mail: sulistyawatisuyanto@gmail.com
}

\begin{abstract}
Jurug Gede Waterfall is a new tourist destination in Gunungkidul due to accessibility and close access to other destinations. This location relies on a not permitted waterfall; consequently, in the dry season, the waterfall can not exist as a tourist view. In another side, in surrounding the waterfall, available a lot of natural resources such as bamboo and wood that can be used as an alternative to building something creative for the tourist destination. PKM was carried out in several stages: socialization with partners, community and related parties, training and workshop. The solutions offered by the PKM program include three main things: empowering local potentials, improving the quality of managers in healthy tourism management and improving the quality of human resources supporting tourism (surrounding residents). The three main activities will be carried out through community empowerment, training, workshops and infrastructure support.
\end{abstract}

Keywords - Healthy Tourism, Health Promotion, Empowerment, Community

\begin{abstract}
Abstrak
Air Terjun Jurug Gede merupakan primadona wisata baru di Kabupaten Gunungkidul. Hal ini dikarenakan akses yang mudah dan terintegrasi dengan obyek wisata lain. Sayangnya, debit air terjun tersebut tidak permanen sepanjang tahun, sehingga saat musim kemarau obyek wisata ini tidak bisa diandalkan secara permanen. Padahal dari sisi sumberdaya, tersedia tanah kosong dan beberapa produk lokal seperti bambu dan kayu yang dapat dimanfaatkan sebagai penunjang wisata, selain air terjun itu sendiri. PKM dilaksanakan dengan beberapa tahap antara lain: sosialisasi, pelatihan penguatan kelembagaan mitra, pembuatan wahana outbond dengan memberdayakan masyarakat, pelatihan penggunaan media monopoli sebagai edukasi kesehatan, workshop pembuatan variasi outbond dan jalurnya serta terakhir penyuluhan promosi kesehatan dengan video drama pada remaja. Solusi yang ditawarkan oleh program PKM ini meliputi tiga hal: pemberdayaan potensi lokal, peningkatan mutu pengelola dalam manajemen wisata sehat dan peningkatan mutu SDM pendukung wisata. Tiga kegiatan utama tersebut akan dilaksanakan melalui pemberdayaan masyarakat, pelatihan, workshop dan dukungan sarana-prasarana.
\end{abstract}

Kata kunci-Wisata Sehat, Promosi Kesehatan, Pemberdayaan, Masyarakat

\section{PENDAHULUAN}

Obyek wisata Jurug Gede merupakan obyek wisata baru yang berbentuk air terjun resmi dibuka pada tanggal 24 Desember 2014. Obyek ini dikelola oleh Kelompok Sadar Wisata (POKDARWIS) Jurug Gede, yang beralamat di Dusun Gembyong, Ngoro-oro, Patuk, Gunungkidul, DIY. Pokdarwis bersinergi dengan pemerintah desa setempat membangun bersama tujuan utama untuk memperbaiki perekonomian masyakat Dusun Gembyong. Dusun ini merupakan desa perbatasan dengan Sleman, SIY. Dusun Gembyong dulunya memiliki tingkat perekonomian yang rendah jika dibandingkan dengan dusun lainnya di Desa Ngoro-oro. Miliki luas wilayah 62.45 ha, Gembyong didiami penduduk sebanyak 276 jiwa yang terbagi dalam 5 RT dan 1 RW [1]. Mayoritas penduduk bermata pencaharian sebagai petani lahan kering dan semusim. 
Program Kemitraan Masyarakat (PKM) ini diselenggarakan dengan menggandeng POKDARWIS Jurug Gede sebagai mitra. Jarak Mitra terhadap Kampus 3 UAD, Janturan, Umbulharjo, Yogyakarta diperkirakan $\pm 21 \mathrm{~km}$. Mitra berperan sebagai host pada setiap kegiatan yang diusung oleh pengusul dan berperan sebagai agen edukasi kepada masyarakat pengunjung melalui sarana prasarana edukasi yang akan disediakan pada obyek wisata tersebut.

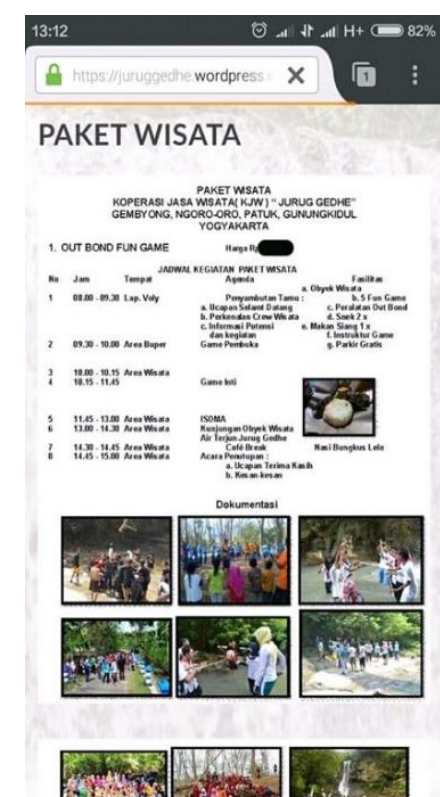

Gambar 1. Leaflet Paket Wisata di Air Terjun Jurug Gede

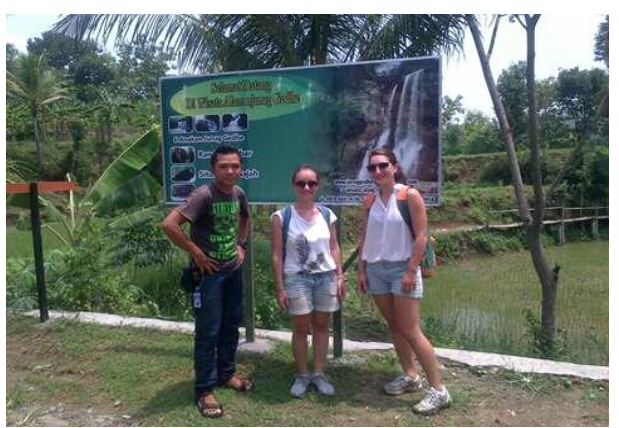

Gambar 2. Plakat di pintu masuk objek wisata

Seiring dengan usaha pemerintah Kabupaten Gunungkidul dalam mendongkrak protensi wisata, Obyek Wisata Jurug Gede ini mulai dikembangkan walaupun masih dalam tahap awal. Dukungan pemerintah Kabupaten Gunungkidul terhadap obyek wisata ini terlihat dengan dibangunnya akses jalan penghubung antar kabupaten yang menghubungkan Kabupaten Sleman dan Gunungkidul, sebagai akses jalan tembus yang telah diresmiskan pada 10 januari 2018 [2]. Jalan tembus wisata tersebut melewati beberapa obyek antara lain yang saat ini sudah exist, yaitu: Air Terjun Jurug Gede, Gunung Api Purba Nglanggeran, Topeng Bubung, 4G Ngalang dan deretan pantai di selatan Gunungkidul.

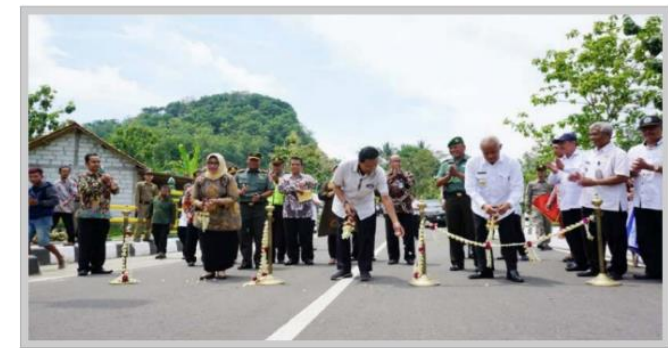

Gambar 3. Peresmian Jalan dan Jembatan Sembada Handayani [3], [4] 
Dusun Gembyong sebagai wilayah pedesaan memiliki potensi lokal berupa bambu dan kayukayu besar yang dapat dimanfaatkan sebagai media outbond di lokasi Jurug Gede. Outbond merupakan wahana yang menjadi daya tarik tersendiri pada setiap obyek wisata, seperti halnya di Karanganyar [5]. Potensi budaya juga dimiliki Mitra yaitu seni karawitan yang dimainkan oleh warga di wilayah tersebut. Disisi lain pengetahuan warga dan pengelola tentang konsep wisata sehat belum dimaknai sebagai bagian terintegrasi untuk mengantisipasi perilaku negatif karena dampak pariwisata yang berkembang. Dari hal tersebut maka potensi lokal yang tersedia melimpah harus dikembangkan namun dengan mengantisipasi dampak buruk suatu perkembangan tersebut

Promosi kesehatan dapat dilakukan dengan berbagai cara termasuk melalui permainan edukasi kesehatan. Monopoli, ular tangga dan video drama sudah terbukti efektif digunakan sebagai media promosi kesehatan termasuk di kalangan remaja [3][6][7][5]. Dua media promosi ini akan ditransfer kepada Mitra sebagai bagian terintegrasi program yang diusung. Harapannya dengan media ini maka pengetahuan remaja, masyarakat dan pengunjung dapat meningkat ketika menikmati wisata Jurug Gede. Sehingga dampak negatif perkembangan wisata dapat diminimalkan.

Hal yang mendasari program ini adalah bahwa Air Terjun Jurug Gede merupakan obyek wisata semusim karena debit air terjun yang tidak permanen sepanjang tahun. Sementara itu, lahan disekitar lokasi masih tersedia dengan beberpa potensi lokal seperti bambu dan kayu, namun belum termanfaatkan secara maksimal karena keterbatasan sumberdaya seperti dana dan kemampuan pengelola dalam menuangkan ide. Beberapa masalah kesehatan masih terjadi di Dusun Gembyong dan Desa Ngoro-oro, seperti rendahnya pengetahuan reproduksi remaja, serta pengetahuan masyarakat tentang beberapa penyakit sehingga perlunya antisipasi perubahan perilaku karena berkembangnya pariwisata. Berdasarkan latar belakang kondisi diatas maka Jurug Gede dapat dimanfaatkan sebagai penguat perekonomian masyarakat serta sebagai wadah promosi kesehatan guna memberikan edukasi masyarakat setempat dan luas yang berkunjung ke lokasi ini

Tabel 1. Aset dan potensi yang sudah dimiliki saat ini

\begin{tabular}{lll}
\hline No & \multicolumn{1}{c}{ Nama set } & \multicolumn{1}{c}{ Unit } \\
\hline 1 & Loket tiket masuk ke obyek wisata & 1 \\
\hline 2 & $\begin{array}{l}\text { Jalan penghubung antar kabupaten (Sleman- } \\
\text { Gunungkidul) sebagai akses paket wisata Gunungkidul }\end{array}$ & Paket \\
\hline 3 & Lahan kosong hibah yang belum termanfaatkan & Paket \\
\hline
\end{tabular}

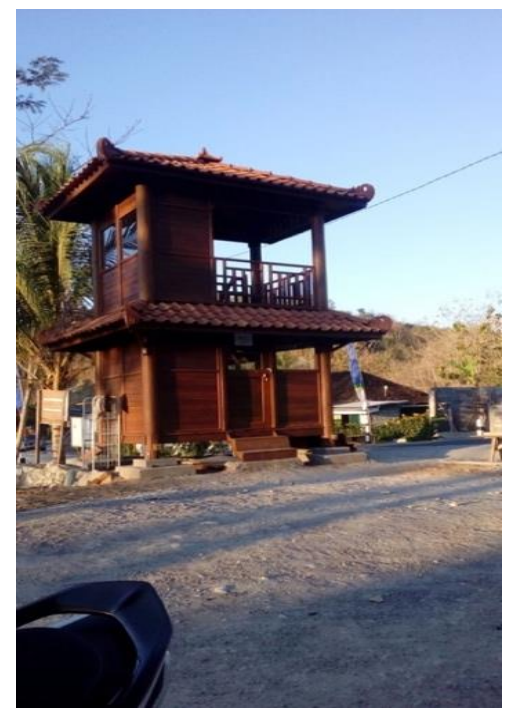

Gambar 4. Gardu tiket masuk objek Wisata Jurug Gede 


\section{METODE}

Program Kemitraan Masyarakat ini dilaksanakan dalam beberapa tahapan, yaitu:

\section{Sosialisasi program PKM}

Sosialisasi program diberikan kepada kelompok masyarakat yang didampingi oleh tokoh masyarakat setempat.

\section{Pembuatan wahana outbond}

Aktifitas ini merupakan sinergi antara mitra dan pengusung. Dimana mitra menyediakan tempat dan tenaga sebagai lokasi dibangunnya wahana outbond dimaksud. Potensi lokal lain yang akan dimanfaatkan adalah bambu "petung" dan akar kayu yang tersedia dengan melimpah sebagai alat. Sementara itu pengusung akan mensupport dengan bahan yang tidak tersedia seperti tali-tali, semen, dan cat.

\section{Pelatihan permainan edukasi ular tangga}

Pembuatan wahana portable ular tangga kemudian dilanjutkan dengan uji coba pada kepada siswa SD dan SMP secara terbatas untuk mengetahui kegunaan dan efektifitasnya.

\section{Penyuluhan promosi kesehatan untuk wilayah pariwisata utamanya kepada remaja di} lokasi

Akan disajikan drama melalui video promosi kesehatan dengan sasaran remaja. Tujuan dari kegiatan ini adalah mencegah perilaku menyimpang remaja sebagai efek berkembangnya daerah wisata.

\section{Pelatihan karawitan untuk promosi kesehatan}

Kegiatan ini dilakukan sinergi antara tim dengan kelompok karawitan. Tim pengabdian menyusun syair promosi kesehatan dengan tema mendukung Germas. Kemudian oleh kelompok karawitan syair tersebut di- arrangement menjadi gending jawa.

\section{Penguatan kelembagaan, pengorganisasian, manajemen dan pemasaran}

Dalam kegiatan ini akan diberikan materi tentang leadership (kepemimpinan), teamwork dan penguatan manajemen. Kegiatan ini bertujuan untuk memupuk rasa memiliki terhadap organisasi dan menjaga organisasi dapat menjalankan perannya secara continue dan terjamin keberlanjutannya.

\section{HASIL DAN PEMBAHASAN}

Program Kemitraan Masyarakat ini masih terus dikembangkan. Mitra yaitu Pokdarwis Jurug Gede berperan aktif dalam kegiatan ini dengan antusiasme tinggi melalui pemberdayaan. Program dijalankan sesuai dengan rencana metode yang direncanakan. Sosialisasi dilakukan kepada pemerintah desa setempat dan unsur terkait terhadap kegiatan ini. Pada kegiatan tersebut dijelaskan tentang program diusung serta target dari kegiatan. Para peserta menyatakan mendorong dan mendukung kegiatan ini karena berkaitan dengan peningkatan kapasitas Jurug Gede agar memberi dampak positif baik secara ekonomi maupun infrastruktur kepada masyarakat luas di Desa Ngorooro. Hal ini dikarenakan sentuhan pengembangan dari pihak ketiga sangat mereka nantikan.

Pembangunan wahana outbond dilaksanakan bersinergi antara pengusung program dan Pokdarwis Jurug Gede melalui konsep pemberdayaan masyarakat. Tim pengusung memberikan dukungan konsep, material dan kebutuhan bahan pembuatan wahana outbound. Sementara itu Pokdarwis dan masyarakat melakukan kerja bakti pembuatan wahana yang direncanakan. Pemberdayaan merupakan suatu konsep pengelolaan sumberdaya lokal atau pembangunan yang berorientasikan pada manusia dengan tujuan akhir memberikan kesempatan pada masyarakat untuk menunjukkan eksistensi dirinya [8]. Pemberdayaan masyarakat merupakan suatu usaha untuk menjaga keberlangsungan program yang dilakukan karena masyarakat merasa memiliki terhadap prosesnya. 

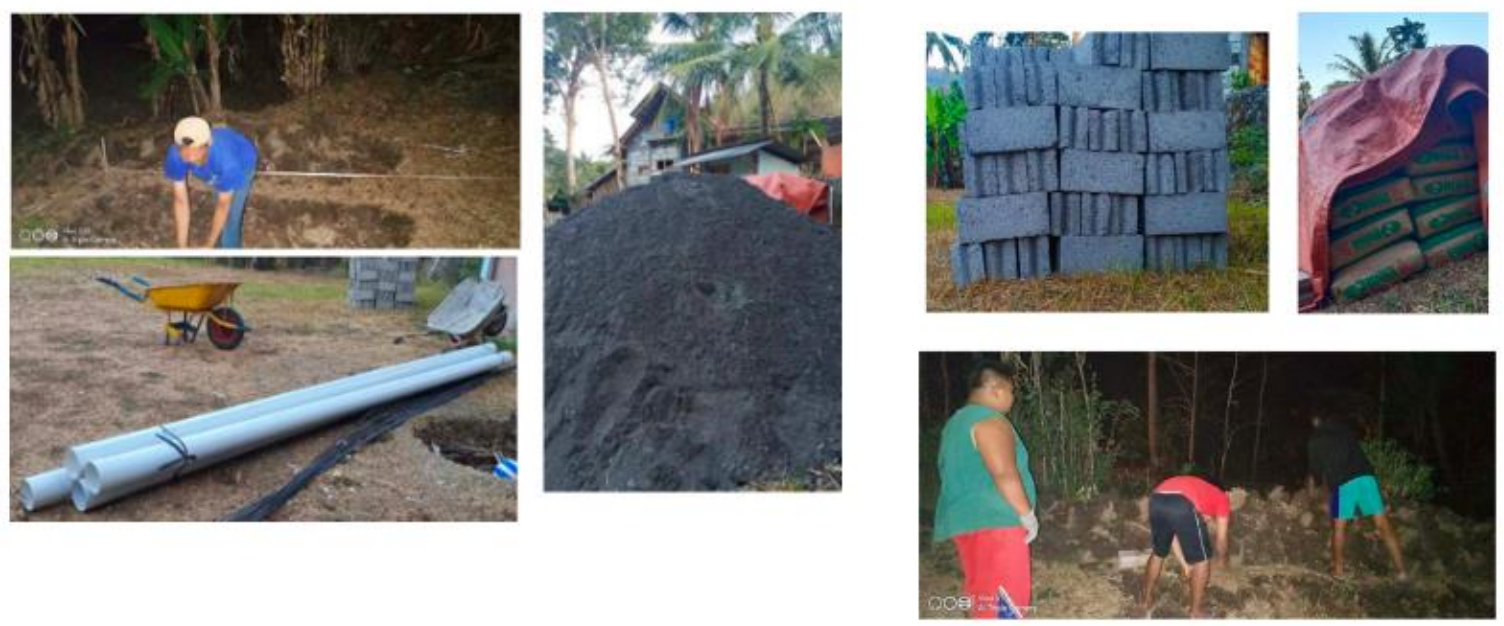

Gambar 5. Kompilasi protret pemberdayaan masyarakat pembangunan wahana outbond Jurug Gede

Pelatihan permainan edukasi kesehatan dengan menggunakan papan ular tangga raksasa menyasar anak-anak SD dana tau SMP. Mereka diharapkan dapat bermain sekaligus belajar. Pembuatan media promosi kesehatan, dilakukan dengan beberapa cara yaitu melalui permainan outbond edukasi dengan menyajikan berbagai pertanyaan kesehatan meliputi pertanyaan Perilaku Hidup Bersih dan Sehat (PHBS), Kesehatan Lingkungan, Kesehatan Reproduksi dan Pencegahan Penyakit. Pertanyaan yang diberikan adalah pertanyaan singkat. Topik sanitasi lingkungan dan PHS yang diberikan adalah seputar jenis sanitasi lingkungan di sekolah, waktu mencuci tangan, pengolahan sampah, PHBS, gosok gigi dan 3M. Pertanyaan kesehatan reproduksi remaja antara lain tentang manusia sebagai makhluk sosial, menstruasi pada wanita, tanda-tanda seksual dan dampak negatif kehamilan dini. Pertanyaan perubahan iklim diberikan sebagai bagian dari pengetahuan lingkungan. Pertanyaan diberikan seputar pengertian perubahan iklim dan dampak perubahan iklim.

Untuk mendukung penyelenggaraan Outbound Dan Edukasi Kesehatan di Jurug Gede, penyiapan sumberdaya yang sehat dan berpengetahuan mutlak dilakukan. Hal ini dengan tujuan untuk mencegah perilaku yang menuju shock culture yang mengarah kepada kegiatan negative, seperti sex bebas dan pelecehan seksual ketika obyek ini ramai dikunjungi wisatawan. Tim pengabdian melakukan sosialisasi sex pra nikah kepada siswa SMP setempat juga pembuatan video pencegahan anti pelecehan seksual keada anak SD. Kegiatan ini mendapat sambutan hangat baik dari pihak sekolah maupun peserta.

Selain kesehatan, tim pengabdian kepada masyarakat juga memiliki tujuan memberdayakan budaya setempat yaitu karawitan. Pada program ini, kelompok karawitan dilatih untuk menggubah lagu yang syairnya berisi tentang anjuran Gerakan Masyarakat Sehat (GERMAS). Seperti diketahui bahwa pemerintah Indonesia mencetuskan GERMAS pada tahun 2017 [9]. GERMAS merupakan suatu aktifitas yang bertujuan mencegah berbagi penyakit melalui hidup sehat yaitu dengan mengkonsumsi sayur dan buah, menghidari rokok, hidup tanpa alkohol serta berolahraga [9][10].

Penguatan kelembagaan, pengorganisasian, manajemen dan pemasaran dilakukan oleh tim pengabdian setelah semua wahana dan sarana lain selesai dibangun. Kegiatan ini dilakukan dengan workshop langsung bersama antara tim dengan Pokdarwis. Workshop dilakukan dengan ujicoba outbound dengan melibatkan siswa SD dan SMP kemudian secara langsung jalannya outbound dipandu oleh Pokdarwis dengan arahan tim pengabdian masyarakat. Selain itu, secara bersama, tim dan Pokdarwis menyusun buku paket outbound yang akan digunakan sebagai media promosi.

Pengabdian kepada masyarakat ini sudah berjalan namun masih perlu pendampingan lebih lanjut. Hal-hal yang masih perlu dilakukan antara lain, bagaimana menarik wisatawan lebih banyak yang sifatnya masal. Hal ini perlu didorong dengan cara membangun jejaring dengan pihak-pihak luar, seperti sekolah, instansi maupun perusahaan swasta guna menjaga keberlangsungan tempat wisata tersebut. 


\section{KESIMPULAN}

Pengabdian masyarakat ini sedang berjalan dengan baik dan lancar. Mitra berpartisipasi aktif dalam kegiatan ini sehingga pengusung dan mitra bersinergi menyelesaikan pekerjaan secara bersama-sama. Kegiatan kedepan masih perlu dibina dengan tujuan untuk meningkatkan kualitas dan kapasitas pengelola obyek wisata Jurug Gede ini.

\section{UCAPAN TERIMA KASIH}

Terima kasih kepada Direktorat Riset dan Pengabdian kepada Masyarakat Direktorat Jenderal Penguatan Riset dan Pengembangan Kementerian Riset, Teknologi, dan Pendidikan Tinggi Republik Indonesia yang telah memberikan dana hibah Program Kemitraan Masyarakat Tahun Anggaran 2018-pelaksanaan tahun 2019.

\section{DAFTAR PUSTAKA}

[1] Y. T. Aditya, "Pengembangan Permainan Ular Tangga Sebagai Media Promosi Kesehatan dalam Meningkatkan Pengetahuan Penyelahgunaan NAPZA pada Remaja Sekolah Menengah Atas," UNIVERSITAS MUHAMMADIYAH MALANG, 2013.

[2] C. Amelia, "Efektifitas Permainan Ular Tangga Untuk Meningkatkan Pengetahuan Tentang Bahaya Rokok Siswa Kelas VII dan VIII SMP Ma'arif NU Tegal Tahun 2010," 2010.

[3] A. Meridiana, "Peresmian Jalan dan Jembatan Sembada Handayani," ngoro-oro.desa.id, 2018.

[4] Desa Ngoro-oro, "Peresmian Jalan dan Jembatan Sembada Handayani," Web Page, 2018. [Online]. Available: http://ngoro-oro.desa.id/first/artikel/165-PERESMIAN-JALAN-DANJEMBATAN-SEMBADA-HANDAYANI. [Accessed: 04-Jun-2018].

[5] D. A. Harjunanto, "Aktifitas outbond sebagai salah satu daya tarik wisata di Kabupaten Karanganyar," Universitas Sebelas Maret, 2008.

[6] R. Y. R. Saleh, I. Farisa, D. Arya, and I. Afriandi, "Film yang Efektif sebagai Media Promosi Kesehatan bagi Masyarakat An Effective Movie as Health Promotion Media for Community," $J S K$, vol. 2, no. 2, pp. 70-78, 2016.

[7] F. A. Imran, "Pengaruh Penyuluhan Kesehatan Melalui Media Video Terhadap Peningkatan Pengetahuan Remaja Putri tentang Dampak Abortus Provokatus Kriminalis di Kelas X SMAN 2 Gowa," Universitas Islam Negeri Alauddin, 2017.

[8] L. Sugiri, "Peranan Pemerintah Daerah dalam Pemberdayaan Masyarakat," Publica, vol. 2, no. 1, pp. 56-65, 2012.

[9] Kementrian Kesehatan RI, Gerakan Masyarakat Hidup Sehat. Indonesia, 2017.

[10] Kementerian Kesehatan Indonesia, "GERMAS Wujudkan Indonesia Sehat," Web, 2016. [Online]. Available: http://www.depkes.go.id/article/view/16111500002/germas-wujudkanindonesia-sehat.html. [Accessed: 27-Aug-2019]. 